\title{
Percepciones de estudiantes uruguayos sobre sus aprendizajes durante la enseñanza remota de emergencia
}

\author{
Uruguayan students perceptions about their learning during \\ emergency remote teaching
}

\author{
Claudia Cabrera Borges \\ CeRP del Centro-cfe-anep. \\ claudiaanahi@gmail.com \\ https://orcid.org/0000-0002-1419-6791 \\ CECILIA CANZIANI SANDRO \\ CeRP del Centro- CFE- ANEP \\ ceciguticeci@gmail.com \\ https://orcid.org/0000-0002-4993-4029 \\ GABRIELA MARTÍNEZ MUSTO \\ CeRP del Centro-CFE-ANEP \\ agabrielamm@gmail.com \\ https://orcid.org/0000-0001-7655-7874
}

\section{Resumen}

La presente comunicación da cuenta de los hallazgos obtenidos en un estudio realizado en Uruguay en junio de 2020, respecto a la visión de los estudiantes de educación media formal, en referencia a las propuestas recibidas de sus docentes $y$, a los aprendizajes alcanzados en la virtualidad durante el período de confinamiento por la pandemia por SARS-CoV-2. En lo que refiere a lo metodológico, se aplicó un cuestionario autoadministrado a estudiantes de educación media de centros públicos y privados que incluyó preguntas orientadas a un tratamiento de datos cuantitativo y otras cualitativo. Los hallazgos muestran preferencia en cuanto a la modalidad, sincrónica o asincrónica, por aquella que utilizaron con más frecuencia sus docentes para la presentación de consignas. En cuanto al tipo de recursos prefirieron los que incluyen textos con imágenes y videos y, tareas del tipo de responder preguntas. Los resultados cuestionan el uso exclusivo de un solo canal para el procesamiento de la información; el escaso peso que los estudiantes le adjudican a recursos tales como simuladores y juegos para su aprendizaje y demuestran la importancia de propuestas que jerarquicen contenidos y guíen al educando en el aprendizaje virtual. Además, se evidenció que la percepción de los encuestados no coincide con los estándares de enseñanza en línea, sino con las características de la enseñanza remota de emergencia. La percepción de que la experiencia constituyó un desafío importante con múltiples y desconocidas dificultades, pero que dejó enseñanzas positivas tanto a docentes como a estudiantes, parece ser una visión generalizada.

Palabras clave: Pandemia, enseñanza remota de emergencia, aprendizajes 


\section{Abstract}

This communication gives an account of the findings obtained in a study carried out in Uruguay in June 2020, regarding the vision of students of formal secondary education, in reference to the proposals received from their teachers and, to the learning achieved in virtuality during the period of confinement due to the SARS-CoV-2 pandemic. With regard to the methodology, a self-administered questionnaire was applied to high school students from public and private schools that included questions oriented toward a quantitative and other qualitative data treatment. The findings show preference in terms of the modality, synchronous or asynchronous, for the one that their teachers used most frequently for the presentation of instructions. Regarding the type of resources, they preferred those that include texts with images and videos and tasks such as answering questions. The results question the exclusive use of a single channel for information processing; the low weight that students assign to resources such as simulators and games for their learning and demonstrate the importance of proposals that prioritize content and guide the learner in virtual learning. In addition, it was evidenced that the perception of the respondents does not coincide with the online teaching standards, but rather with the characteristics of emergency remote teaching. The perception that the experience constituted an important challenge with multiple and unknown difficulties, but that it left positive lessons for both teachers and students, seems to be a generalized view.

Keywords: pandemic, emergency remote teaching, learning

\section{Introducción}

En Uruguay el día viernes 13 de marzo del año 2020, se El presente estudio se sitúa temporalmente en el mes de junio del 2020, a tres meses de la aparición de los primeros casos positivos de COVID -19 en Uruguay. En consonancia con lo ocurrido en otros países latinoamericanos, esos meses se caracterizaron por la enseñanza virtual exclusiva, al menos en lo que respecta a las instituciones públicas y privadas de educación media, nivel en el que se hace foco en la presente comunicación.
En ese marco se resignifica lo que plantean Burbules y Callister, cuando expresan que "Las nuevas tecnologías se han convertido en un problema educativo, un desafío, una oportunidad, un riesgo, una necesidad..." (Burbules y Callister, 2006, p.14). Si bien en los últimos años las dudas sobre las tecnologías digitales transitaron por si se debían utilizar o no en el ámbito educativo, en el contexto de pandemia, el énfasis está en cuáles utilizar y de qué manera, para lograr aprendizajes de calidad. Necesarias, sin lugar a dudas, pero también este contexto ha sido una oportunidad forzosa de rever una serie de prácticas educativas cuyos resultados están fuertemente cuestionados. Las preguntas relacionadas con el cómo y con qué fines utilizar las tecnologías digitales, cobran especial relevancia en el contexto actual.

El pasaje a la virtualidad total supuso que se comenzaran a utilizar diversas modalidades de comunicación con los estudiantes y, particularmente en Uruguay, se destaca el uso de la plataforma Crea, que es la que ofrece el Plan Ceibal. Esta plataforma ya se utilizaba previo a la crisis, aunque de acuerdo a lo que plantean Failache, Katzkowicz, Machado (2020), no estaba pensada para su uso de forma exclusiva, es decir, en sustitución de la presencialidad. Una dificultad adicional de la interrupción de los cursos presenciales a pocas semanas de iniciados los mismos, es que los docentes no tuvieron tiempo de conocer a sus estudiantes, para adecuar su propuesta didáctica a sus intereses y necesidades.

A pesar de que en Uruguay el acceso a los dispositivos es uno de los más altos de Latinoamérica (CEPAL, 2020), todavía persisten dificultades en lo que respecta a la conectividad, lo que se complejiza aún más con un escenario de confinamiento en el que la educación se traslada a los hogares, otorgando a las familias la responsabilidad de sostener los procesos educativos para que estos se concreten. La virtualidad exclusiva obligó a que las tecnologías digitales formaran parte del repertorio de herramientas educativas que los docentes debieron incorporar a sus prácticas. Las distintas dificultades que se pueden haber presentado para los aprendizajes, tales como no contar con un espacio adecuado, distractores presentes en el hogar, el tiempo frente a la pantalla, o la falta de conectividad, hacen más que nunca que el tiempo dedicado a realizar las actividades propuestas sea muy valioso como para perderlo en actividades que no tengan un propósito educativo claro y relevante para la formación del estudiante. Por qué enseñar con ese recurso, en qué contexto, con qué estudiantes, en qué tiempo y con qué otros recursos, son todas preguntas que un docente se realiza frente a recursos tradicionales, pero en el contexto digital se suman otras variables 
como la posibilidad de conectividad, el tipo de dispositivo del que disponen, o las propias habilidades digitales de los estudiantes.

En la misma línea de lo expuesto, desde organismos internacionales como CEPAL (2020), se hace referencia a los cambios ocurridos en la educación en ese tiempo:

La pandemia ha transformado los contextos de implementación del currículo, no solo por el uso de plataformas y la necesidad de considerar condiciones diferentes a aquellas para las cuales el currículo fue diseñado, sino también porque existen aprendizajes y competencias que cobran mayor relevancia en el actual contexto (p.4).

De acuerdo a lo que se expone en el mencionado informe, se torna imprescindible identificar aquellas competencias requeridas para continuar aprendiendo y se identifica la necesidad de profundizar el carácter integral y humanista de la educación (CEPAL, 2020).

Hoy más que nunca las instituciones escolares no son las depositarias exclusivas del saber, la existencia de estas tecnologías lo reafirman, y desafían a los docentes a definir los momentos para utilizarlas, los propósitos y el tipo de producto de aprendizaje que dé cuenta del desarrollo efectivo de las habilidades dispuestas en la currícula escolar. Estas herramientas tecnológicas ofrecen la posibilidad de potenciar el aprendizaje ubicuo como lo plantea Burbules y Callister (2006), para aprender en cualquier momento y en cualquier lugar a lo que se agrega: para aprender de formas más genuinas y aproximadas a las que utilizan los profesionales y expertos en la vida diaria.

Otro aspecto a considerar en relación con los aprendizajes, es el énfasis que se hace desde UNESCO (2020), al impacto que tuvo la interrupción de la presencialidad en la formación social de los educandos al afirmar que: "Cuando las escuelas cierran, muchos niños y jóvenes pierden el contacto social que es esencial para el aprendizaje y el desarrollo" (s/p).

En ese marco, la presente comunicación tiene como propósito dar respuesta de cuál es la visión de los estudiantes de educación media consultados, respecto a qué formatos y recursos prefirieron durante su tránsito educativo en virtualidad exclusiva y cómo perciben que cada tipo de propuesta virtual favoreció en mayor o menor medida su comprensión.

\section{Antecedentes y líneas teóricas sustentan el análisis}

Un antecedente de especial relevancia es la encuesta realizada por organismos oficiales a los docentes uruguayos en julio del 2020 (ANEP, 2020). En la misma se expresa que si bien en educación primaria, tanto el nivel de comunicación como de respuesta a las tareas fue muy elevado (83\%), los valores descienden sustancialmente respecto a educación media ( $56 \%$ en el Consejo de Educación Secundaria y 49\% Consejo de Educación Técnico Profesional).

La misma encuesta ofrece como dato, además, que los docentes manifiestan que se usaron diversos medios tecnológicos para el desarrollo de las diferentes actividades, dentro de los que se destacan como principales vías Whatsapp y la plataforma CREA del Plan CEIBAL. Con menos frecuencia son referidos los contactos vía zoom y el correo electrónico.

En lo que respecta específicamente a los aprendizajes, la percepción predominante en los docentes corresponde a que considera que sus estudiantes lograron aprendizajes medios o moderados (49\%). De acuerdo a lo que expresa el informe si bien esta predominancia es la que se constata, respecto a los docentes en general, en educación media la percepción de escasos aprendizajes de los estudiantes en tiempos de virtualidad exclusiva, son mayores en comparación a lo percibido por los maestros de primaria (ANEP, 2020, p.7).

También interesan las dificultades constatadas por los docentes, entre las que se destaca: "tener que enseñar sin el contacto cara a cara con los estudiantes" (ANEP, 2020, p.7). Carecer de contacto presencial con los estudiantes trajo consigo dificultades vinculadas al diseño de actividades de enseñanza y evaluación a distancia, situaciones valoradas como "problemáticas" o "muy problemáticas" por aproximadamente 6 de cada 10 docentes. A las mencionadas se suman las dificultades que refieren a compatibilizar la enseñanza con tareas personales de los docentes. Finalmente, aparecen con menor recurrencia, aunque son igualmente relevantes, las dificultades vinculadas a lo tecnológico, que van desde el acceso a equipos, la conectividad a internet y las habilidades tecnológicas, tanto propias, como de los estudiantes. En estrecha relación con lo mencionado el estudio expresa que: "Ios docentes sí identificaron el acceso y el uso de las tecnologías por parte de los estudiantes como uno de los obstáculos a su participación" (ANEP, 2020, p.8). A nivel local autores como Failache, Katzkowicz, Machado, (2020), destacan la relevancia de formar a los docentes para 
estos nuevos escenarios. En la misma línea Fardoun et. al $(2020, p .8)$, identifican la formación didáctica y en competencias digitales de los educadores como una de las claves de la transformación digital. Destacan, además, que es imprescindible el desarrollo de competencias también en los estudiantes dado que son quienes deben asumir un mayor grado de autonomía en sus aprendizajes.

\subsection{Enseñanza en línea versus enseñanza remota de emergencia}

Transitar hacia la enseñanza en línea en tiempos en que prima la ubicuidad de los aprendizajes, caracterizados por darse en cualquier tiempo y espacio, parece concebirse como necesidad, pero, a decir de Hodges et. al (2020), la situación de pandemia aceleró procesos de forma tal que los cambios se dieron de manera muy acelerada y sin contar con la suficiente preparación de los actores involucrados. Los autores mencionados afirman que, si bien el aprendizaje en línea goza de menor prestigio respecto al que se da en el intercambio cara a cara, existen múltiples investigaciones que dan cuenta de lo contrario. Sin embargo, este tránsito tan apresurado que se dio hacia la virtualidad por el contexto de pandemia, podría haber mostrado más las debilidades que las fortalezas.

Es en ese marco, interesa referir a la propuesta de Hodges et. al (2020) de diferenciar los conceptos de enseñanza en línea y enseñanza remota de emergencia (ERE). Este último concepto se utiliza para referir a la enseñanza virtual impartida en tiempos de crisis. Mientras que la enseñanza en línea se caracteriza por un diseño y planificación cuidadoso y específico que conlleva múltiples decisiones didácticas centradas en el sujeto que aprende a través de dispositivos tecnológicos, la ERE ,en general, no cuenta con estos procesos sistemáticos que ofrecen ciertas garantías de calidad. Los autores identifican nueve dimensiones que inciden en la toma de decisiones didácticas: modalidad, ritmo, proporción alumno-instructor, pedagogía, rol del instructor en línea, rol del estudiante en línea, sincronía de comunicación en línea, rol de las evaluaciones en línea y fuente de retroalimentación. Otro aspecto que destacan es la necesidad de inversión para brindar apoyo a los estudiantes. En contraposición con ello se encuentra la ERE en la que, además de la celeridad en los tiempos que obstaculizan una planificación apropiada, los recursos destinados tampoco son los acordes a lo requerido. La misma idea se reafirma desde UNESCO (2020), cuando se identifica la necesidad de contar con los recursos humanos y técnicos para afron- tar el desafío que supone trasladar el aprendizaje de las aulas a los hogares a gran escala y con prisa. Fardoun et. al $(2020$, p.7), complementan lo mencionado diciendo que: "la emergencia sanitaria ha supuesto la adaptación urgente de la docencia presencial, de forma improvisada, y sin contar con los recursos necesarios para una correcta transformación digital de la docencia a la modalidad virtual".

Corresponde mencionar, además, que los propósitos de una y otra enseñanza son diferentes. En tanto en la primera se busca lograr una mayor calidad, en la segunda se pretende proporcionar acceso temporal a la instrucción y los apoyos educativos de una manera que sea rápida de configurar y esté disponible de forma confiable durante una emergencia o crisis.

La precisión conceptual realizada interesa en tanto se pretende conocer cómo percibieron los estudiantes las propuestas educativas recibidas en tiempos de enseñanza remota de emergencia y qué preferencias identifican respecto a las mismas. Si bien la información recogida no pretende dar cuenta de la calidad de las propuestas ofrecidas en línea, sí aporta luz sobre cómo percibieron los estudiantes consultados lo que se les ofreció en tiempos de virtualidad exclusiva, lo que puede brindar algunas ideas que permitan reflexionar sobre cómo mejorar las propuestas de enseñanza que promuevan el e- learning (Electronic Learning -aprendizaje en línea) o b-learning (Blended Learning - combinación de aprendizaje en línea y presencial).

\subsection{E-learning / E-actividades}

Las tecnologías digitales tienen un significativo potencial para favorecer una comprensión más profunda de las ideas o fenómenos en construcción, pero más que un valor en sí mismas, su peso específico radica en el cómo las utiliza el docente, para qué y de qué manera las integra para lograr aprendizajes más profundos en las clases virtuales (Fullan, 2014). Si bien la naturaleza interactiva de las TIC facilita la creación de entornos en los que los estudiantes aprendan haciendo, reciben retroalimentación, refinen su comprensión y construyan conocimiento nuevo, el recurso sólo tiene valor en el marco de la propuesta pedagógica en el que se enmarca.

El aprendizaje en línea o e-learning, es un concepto relevante cuando se alude a la mediación con tecnologías digitales. Este aprendizaje puede llevarse a cabo mediante diferentes modalidades. Según la visión pedagógica a la que responda, puede tratarse de una simple transferencia de información del docente al es- 
tudiante mediante el envío de recursos o utilización de las plataformas como repositorios, o puede ponerse al servicio de promover el desarrollo de competencias y la construcción más autónoma de conocimiento. Es entonces que esta modalidad de enseñanza supone diversos roles para el docente que van desde el lugar en el que el profesor se hace responsable de organizar, diseñar, monitorear y poner en funcionamiento la acción formativa, hasta aquellos en los que únicamente se dedica a ofrecer los contenidos y a evaluar las actividades realizadas por los estudiantes (Cabero y Román, 2006).

Por otra parte, las e-actividad refieren a diferentes acciones que los estudiantes realizan en relación con los contenidos e informaciones que se les ofrece y son presentadas, realizadas o transferidas a través de la red (Cabero y Román, 2006). Las e-actividades pueden convertirse en un factor clave para lograr un aprendizaje en línea de calidad.

En lo que respecta al criterio para la selección de las eactividades Cabero y Román (2006), proponen: pensar en actividades que sean acordes al campo disciplinar en el que se enmarca la asignatura, tener presentes las características de los estudiantes, diseñar propuestas tendientes a movilizar en el estudiante diferentes tipos de capacidades, considerar los intereses y motivación de los estudiantes, atendiendo las posibilidades que ofrece la red para su desarrollo.

Un formato de actividad que con frecuencia es utilizado, y las propuestas virtuales no son la excepción, es la incorporación de preguntas. Un tipo de tarea frecuentemente propuesta a los estudiantes para guiar el proceso de aprendizaje, es el de responder preguntas a partir de textos o videos expositivos. Más allá de aspectos específicos del campo disciplinar de las distintas asignaturas, existen preguntas que se le hacen al conocimiento que son comunes a cualquier campo de estudio y que ayudan a focalizar el abordaje de los problemas en los componentes del pensamiento. El aprendizaje de conocimiento declarativo a partir de la lectura requiere tanto de la comprensión de la información textual como de la elaboración de inferencias. Este formato de tarea enfatiza el uso de la información relevante del texto o video, para responder preguntas que guían a los estudiantes en procesos cognitivos inferenciales y contribuye a centrar la atención en la información relevante (Rubio, et. al, 2020). En contraposición, tiene como efecto negativo el promover la formación de representaciones mentales fragmentadas y parciales del texto. Rubio et al, (2020), investigaron los efectos en el aprendizaje tanto de las preguntas planteadas después de leer un texto, como insertadas den- tro del mismo. Sus resultados muestran que, en ambas condiciones, el procesamiento de la información del texto está altamente definido por el tipo de preguntas planteadas por los docentes y que las preguntas insertadas favorecen que los estudiantes se centren en la información relevante, generan inferencias más precisas y aprendan más en comparación con preguntas formuladas después del texto. Además, detectaron que la facilitación de los procesos cognitivos de identificación y selección de la información relevante fueron beneficiosos para los estudiantes con bajo nivel de conocimientos previos.

La importancia de la práctica de responder preguntas esenciales radica en que conduce al hábito de hacer preguntas esenciales. Elder y Paul (2002) abordan el tema de la importancia de las preguntas esenciales en la calidad del desarrollo del pensamiento humano, tanto cuando los sujetos hablan, escriben, leen como en la vida diaria. Según estos autores, "Las preguntas definen tareas, expresan problemas y delimitan asuntos. Impulsan el pensar hacia adelante." (Elder, Paul, 2002, p. 5). Esto facilita la generación de otras preguntas y la indagación. Las preguntas adecuadas permiten pensar lógicamente sobre los temas, ordenar, clarificar y guiar a los estudiantes sobre los aspectos esenciales de cada tema. Es por ello, que las preguntas esenciales son "la clave para el pensamiento productivo, el aprendizaje profundo y vivir con efectividad."(op. cit. p.5).

Las preguntas pueden ser utilizadas como una potente herramienta para el aprendizaje, y no solo como medio para la evaluación. Existe evidencia de las ventajas de su utilización en situaciones de alta demanda a los estudiantes, como puede haber sido la situación de emergencia sanitaria y educativa por la que se atravesó en el 2020. Una de estas ventajas, es que el planteo de tareas en formato de preguntas permite que el estudiante visualice la tarea completa, medida esta por el número de preguntas que deberá contestar. Un estudio llevado a cabo por la Universidad de Tel Aviv en el que participaron un grupo de estudiantes universitarios (Katzir et al, 2020), mostró que la visualización del final de una tarea motiva a los estudiantes, ya que les permite saber que luego podrán realizar otras actividades más afines a sus intereses. La certeza favorece la movilización de recursos energéticos para alcanzar la meta prevista. Por el contrario, cuando los estudiantes se encuentran exigidos y desconocen los tiempos que le insumirá la realización de una actividad, tienden a repartir las fuerzas comprometiendo así su rendimiento. 


\subsection{Recursos digitales y su vinculación con los aprendizajes}

En el diseño de una estructura virtual para la enseñanza y el aprendizaje, los docentes se encontraron ante la necesidad de elaborar, buscar, seleccionar y valorar recursos digitales para la construcción de los saberes curriculares de cada disciplina. En una situación de enseñanza virtual adecuadamente planificada, resulta útil formular y dar respuesta a preguntas referidas a: ¿qué formatos digitales utilizar para promover el desarrollo de habilidades propias de cada disciplina? ¿Cómo utilizarlos para promover aprendizajes de calidad? ¿qué tipo de procesos cognitivos favorecen? ¿A través de qué formatos en este contexto los estudiantes aprenden mejor?

Sin embargo, la propuesta de enseñanza virtual que analizamos en la presente comunicación no fue producto de una planificación de enseñanza en línea, sino que se ajusta a una propuesta de enseñanza remota de emergencia (ERE). En este contexto donde la optimización del tiempo y de los recursos es esencial, otras dos preguntas claves sin duda deben haber sido: qué es fundamental enseñar y cómo puede un recurso determinado favorecer el desarrollo y comprensión de los conceptos, fenómenos y habilidades claves de la disciplina. Carina Lion (2021), nos invita a reflexionar en torno a qué nos dejó esta experiencia de enseñanza virtual del 2020 y señala la importancia de dar herramientas para la jerarquización disciplinar ante la horizontalidad epistemológica que supone internet. La autora plantea la necesidad de dar herramientas para la autorregulación de los aprendizajes, para la búsqueda de relevancia de los conocimientos; enseñar a jerarquizar para que los estudiantes puedan elegir, discernir los conceptos relevantes y que no sea el algoritmo, la inteligencia artificial, quien decida. Este escenario epistemológico, que obligó a pensar y realizar recortes curriculares con mayor precisión; también posicionó a los docentes y estudiantes en un escenario que ofrece múltiples recursos digitales, que también obligaron a la toma de decisiones.

Pero, ¿qué son los recursos digitales que ofrecen estos contextos tecnológicos? En lo que respecta al concepto de recurso digital, se lo concibe como cualquier elemento en formato digital que pueda ser visualizado y almacenado en un dispositivo electrónico y que pueda ser consultado tanto de forma directa o indirecta a través del acceso a la red. Existen varios modelos de clasificación de recursos digitales, siendo difícil establecer una división tajante, ya que muchos recursos pueden ser incluidos en una u otra categoría de acuerdo a para qué son incluidos en la propuesta pedagógica. Es frecuente encontrarlos agrupados bajo la denominación de recursos multimedia, entendiendo a estos como cualquier recurso que combine más de un formato representacional (por ejemplo, verbal y no verbal) ya sea en una única modalidad sensorial (auditiva o visual), como en una combinación de ambas (Mayer, 2014). De acuerdo a su formato podemos encontrar vídeos, imágenes, podcast de audio, pdfs, libros digitales, páginas web, animaciones de procesos y modelos, simulaciones, aplicaciones para visualizar y registrar fenómenos, juegos, y redes sociales entre muchos otros. El valor de cada uno de ellos en cuanto a las habilidades y procesos cognitivos que permiten desarrollar no es intrínseco, sino que depende de cómo son integrados, la comprensión de su lógica y la facilidad de acceso a los mismos. Un grupo de recursos digitales muy utilizados son los videos. El contenido incluido dentro de esta categoría puede ser variado, desde grabaciones de clases puestas a disposición de los estudiantes, filmación del docente sin elementos de apoyo o con ellos, (como puede ser pizarra física o virtual u otro medio digital como una presentación) explicación de fenómenos de tipo documental o animado, hasta videos de charlas con expertos como lo son las conferencias de formato TEDx. Si bien cada una tiene un valor diferencial, todos tienen en común la utilización de imágenes dinámicas. Los recursos de tipo video utilizados como apoyo para la comprensión de los temas curriculares, pueden enriquecer los mismos a través del vínculo con el mundo real, a partir del contacto con datos reales y expertos disciplinares, brindando la posibilidad no solo de resolver problemas sino también de plantear problemas propios (National Research Council, 2000).

Otra categoría de recursos son las animaciones, simulaciones y juegos. En la web es posible encontrar variados recursos, que permiten emular condiciones reales de trabajo en laboratorio, a través de los cuales los estudiantes pueden interiorizarse con técnicas utilizadas por los científicos en sus investigaciones. En ciencias, los simuladores permiten una aproximación sobre aspectos instrumentales del trabajo de experimentación, brindando datos concretos que facilitan el desarrollo de competencias científicas de gran valor como lo son el análisis de datos o la elaboración de predicciones a partir de hipótesis sobre un fenómeno, etc. (Salomon, 2012).

El predominio de nuestro sentido de la visión por encima de otros sentidos, vuelve muy valioso este tipo de recursos, ya que ayudan a la representación visual de fenómenos, procesos o hechos complejos. Ello no sig- 
nifica necesariamente que se acabe entendiendo más cabalmente el significado de lo que está sucediendo, al utilizar la representación visual de forma exclusiva. Debido a que la memoria de trabajo tiene una capacidad limitada, el exceso de elementos de un mismo tipo (sean imágenes o texto) puede sobrecargar la capacidad de procesamiento cognitivo, por lo que es conveniente activar canales distintos de procesamiento de la información (Mayer, 2014). A su vez una misma vía puede transmitir información a través de múltiples formatos

que demandan un procesamiento y aprendizaje multimedia diferencial. Un mensaje de whatsapp puede incluir texto, audio e imágenes. Con multimedia nos referimos a cualquier presentación que combine más de un formato representacional (por ejemplo, verbal y no verbal) ya sea en una única modalidad sensorial (como puede ser la visual) como en una combinación entre diversas modalidades (Mayer, 2001, 2014) y que conlleve a la utilización de distintas modalidades de procesamiento de la información.

Según la teoría cognitiva del aprendizaje multimedia de Mayer (2001) los seres humanos poseen canales separados para procesar la información visual y auditiva. A través de la vía visual se perciben textos, gráficos, animaciones, videos o ilustraciones y por la vía auditiva narraciones o sonidos ambientales. Una vez que ingresa al sistema cognitivo, dicha información es representada en la memoria de trabajo que mantiene una representación mental del mensaje en forma activa, a medida que se procesa el significado del mismo (Baddeley y Logie, 1999; Mayer, 2014; Rouet, Lowe y Schnotz, 2008 como se citó en Burin, 2020). Otra premisa a destacar de esta teoría es que la comprensión y el aprendizaje efectivo de la información tiene lugar cuando se da un procesamiento activo de esta. Para ello es clave seleccionar la información relevante, organizar las imágenes y las palabras de forma coherente $y$, no menor, integrar la nueva información con el conocimiento previo. A partir de estos supuestos, se desprende que un contenido se aprende más profundamente cuando es presentado combinando distintos formatos de presentación de la información (palabras e imágenes), ya que el procesamiento de información que utiliza más de un canal proporciona ventajas de capacidad, codificación y acceso, en la memoria. La comprensión profunda tiene lugar cuando los estudiantes pueden construir conexiones entre las representaciones verbales y visuales (Mayer, 2014). Según Mayer y Moreno (1998), la utilización de recursos multimedia demanda la utilización de dos representacio- nes mentales (un modelo verbal y un modelo visual) que luego son integradas. Un principio que se desprende de este supuesto es que no todas las combinaciones de recursos multimedia tienen los mismos efectos sobre la solidez de los aprendizajes. La combinación de formato verbal más no verbal (texto más imagen o narración más animación) conduce a representaciones y aprendizajes más ricos y estables que la combinación de modalidades que activan un mismo canal de procesamiento de la información, por ejemplo, de formato verbal (texto más narración).

\subsection{Comunicación sincrónica y asincrónica}

Las herramientas de comunicación sincrónica y asincrónica se utilizan frecuentemente en diversas áreas y la educación es una de ellas. La principal diferencia entre ambas refiere a la simultaneidad con la que se envía y recibe el mensaje.

Para Valverde (2002), la comunicación sincrónica es aquella en la que los usuarios, a través de la red, coinciden en el tiempo y se comunican entre sí a través de texto, audio y/o vídeo, siendo un ejemplo son las videoconferencias. Por el contrario, en la asincrónica los involucrados utilizan el sistema de comunicación en tiempos diferentes. Un ejemplo de este tipo de comunicación es la recepción o el envío de tareas a través de una plataforma educativa, donde el receptor puede leer el mensaje en cualquier momento después de que el emisor lo envíe, sin que se produzca esa simultaneidad en la comunicación.

Cuestas, González y Liberati, (2020), identifican ventajas y desventajas de las actividades propuestas en una y otra forma de comunicación, basados en lo ocurrido a nivel educativo en la actual situación de pandemia que se ha vivido a nivel mundial:

Las actividades sincrónicas permitieron diagnosticar y reformular la enseñanza en tiempo real, a partir de reacciones y consultas de los y las estudiantes. Sin embargo, la exposición ante sus pares generó inhibición al momento de despejar dudas. Las actividades asincrónicas resultaron útiles para la resolución de trabajos prácticos individuales o grupales y permitieron la utilización de material audiovisual como soporte pedagógico, facilitando la construcción del conocimiento. No obstante, basándonos en encuestas realizadas a los y las estudiantes, esta modalidad también impidió despejar dudas de forma inmediata. Además, dificultó el aprendizaje colectivo y la administración inadecuada del tiempo provocó la acumulación de tareas (p.1). 


\section{Metodología}

La base de datos del presente trabajo se obtuvo mediante un instrumento diseñado en formato de formulario Google, destinado a relevar las percepciones de los estudiantes de educación media sobre su experiencia educativa en el primer semestre de 2020, que en Uruguay se desarrolló de forma exclusivamente no presencial, por la situación de confinamiento, debido a la pandemia provocada por el SARS-CoV-2. El instrumento se organizó en tres secciones. La primer sección se enfocó en relevar datos que permitieran caracterizar la población encuestada: edad, sexo, nivel educativo que cursa, tipo de institución (pública o privada) y, departamento de residencia. La segunda sección contenía cinco preguntas orientadas a relevar las percepciones de los estudiantes sobre su experiencia de enseñanza y aprendizaje en la situación de virtualidad exclusiva que impuso el confinamiento. Todas las preguntas de esta sección se formulan como preguntas cerradas con sus correspondientes opciones y se dejó la posibilidad de que el encuestado pudiera agregar otra opción que no estuviera contemplada por las investigadoras, en cada una de las preguntas. De las cinco preguntas que incluía esta sección, dos se orientaron a relevar aspectos vinculados a la comunicación docente - discente durante el período de confinamiento (las que fueron abordadas en un trabajo precedente - Cabrera Borges, Canziani, Martínez, (2020) y otras tres se orientaron a conocer las percepciones de los estudiantes sobre la enseñanza - aprendizaje mediado por las TIC durante dicho período. Para el presente trabajo se incluye, de esta sección, sólo el análisis de estas tres últimas preguntas:

Consulta orientada a conocer qué modalidad considera el estudiante que le ayuda a comprender mejor las consignas dadas por los docentes:

- Comprendías mejor las actividades o tareas propuestas por los docentes cuando éstas... Opciones de respuesta: se planteaban sólo por escrito, se planteaban por videoconferencia, se explicaban únicamente con un vídeo, se explican únicamente con un audio, otro.

Dado que, para esta pregunta, sólo aparecen seleccionadas las opciones sólo por escrito y por videoconferencia, se opta por el análisis agrupado de las respuestas como modalidad asincrónica la opción solo por escrito y como modalidad sincrónica la opción videoconferencia.
Consulta orientada a conocer qué recursos le permitían al estudiante comprender mejor los temas abordados por sus docentes:

- Las propuestas que te ayudaban a comprender mejor los temas, son las que incluían... Opciones de respuesta: sólo texto; texto e imágenes; juegos, animaciones o actividades de simulación; sólo videos, otro.

La tercera consulta se enfocó en conocer qué tipo de actividades, de las que les proponían realizar sus docentes, les ayudaba a aprender más o mejor:

- En referencia a lo que tenías que hacer, ¿cuál de las siguientes actividades te ayudaron a aprender más? Opciones de respuesta: responder preguntas; construir o crear algo (video, infografía, red de ideas, otro); redactar textos; preparar algo para exponer a tus compañeros, otro.

La tercera y última sección del cuestionario, se formula de forma abierta invitando a los estudiantes encuestados a dejar sus reflexiones y comentarios sobre la experiencia educativa vivida en este período. En esta sección se incluye un ítem cuyo propósito es la identificación de aprendizajes por parte de los estudiantes. La consigna les solicitó que completaran la frase: «Lo que más aprendí en este tiempo de no ir al liceo fue...".

Las respuestas al formulario se limitaron a una por estudiante. La encuesta se difundió mediante la red social WhatsApp, desde el 15 de junio hasta el 10 de julio de 2020. Las investigadoras enviaron el enlace del formulario a estudiantes de educación media de distintos departamentos de Uruguay y a docentes que se ofrecieron para aplicarlo a sus estudiantes.

Se alcanzó una muestra de 389 respuestas, en total. Si bien como parte del análisis se realizaron otros cruces vinculados a la primera sección del cuestionario, por ejemplo, respecto al sexo de los encuestados, en esta comunicación para la muestra solo se discriminan las subcategorías: según tipo de institución, pública o privada y según nivel: primer ciclo o segundo ciclo (o bachillerato). Para las tres preguntas consideradas de la sección dos del formulario, se obtiene la abundancia relativa de cada una de las opciones seleccionadas. Se utilizan tablas de contingencia para determinar la probabilidad de asociación entre las variables analizadas en cada pregunta y las subcategorías consideradas (tipo de institución y nivel educativo). Se utilizó test de chi cuadrado para determinar la significación estadística de estas asociaciones. En 
el caso del análisis de la pregunta abierta se realizó una categorización in situ, no apriorística, de las respuestas en base a la evidencia empírica disponible. Se identificaron como categorías los aspectos referidos a lo académico, tecnológico, personal, vincular y otro. A cada una a su vez se la subdividió en subcategorías que permitieron profundizar el análisis.

\section{Resultados}

\subsection{Caracterización de la población encuestada}

El número total de la muestra fue de 389 respuestas. Un $60 \%$ correspondió a mujeres y $39 \%$ a varones, en tanto el $1 \%$ de los encuestados se identificó con la opción otros. En lo que respecta a la distribución en subcategorías por nivel, el $36 \%$ corresponde a primer ciclo (de primero a tercero) y el $64 \%$ a segundo ciclo (de cuarto a sexto). Mientras que la población de estudiantes discriminada en la subcategoría tipo de institución, resultó conformada por un $71 \%$ del ámbito público, en tanto el $29 \%$ declaran pertenecer al ámbito privado.

\subsection{Modalidad en la que los estudiantes recibían las consignas y consideran que las comprenden mejor}

Al ser consultados los estudiantes sobre cuál modalidad, en la que recibían la consigna, les ayudaba a comprender mejor la tarea que le solicitaba el docente, un $61 \%$ manifiesta preferencias por canales asincrónicos con formato de texto escrito mientras que el $39 \%$ de los estudiantes prefiere canales sincrónicos con formato de videoconferencia. Si bien, en general, la modalidad seleccionada como favorecedora de compresión es la asincrónica, se aprecian variantes al momento de discriminar según el tipo de institución y el ciclo.

Al analizar esta información, discriminada por tipo de institución pública o privada, se encontró una asociación significativa entre la preferencia por una determinada modalidad y el tipo de institución $(=4.459$, con $1 \mathrm{gl}$, nivel de significación $p=0.05)$. A su vez, estas preferencias fueron distintas entre el ámbito público y el ámbito privado. Para el primer caso, instituciones públicas, se encontró un $69 \%$ de preferencia por la modalidad asincrónica con un formato de texto escrito mientras que los estudiantes del ámbito privado prefirieron la modalidad sincrónica de videoconferencia (57\%) (Figura 1). Esta preferencia de los estudiantes de instituciones privadas por lo sincrónico, es congruente con que un
$73 \%$ de este estudiantado manifiesta haber utilizado como vía de comunicación zoom (Cabrera Borges, Canziani, Martínez, 2020).

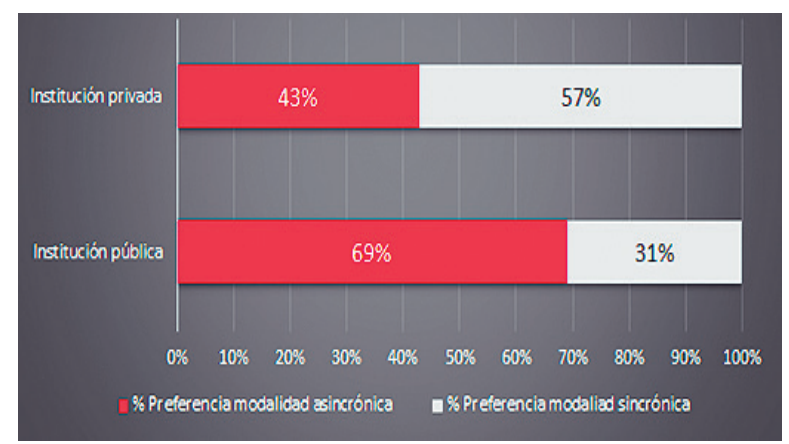

Figura 1. Preferencia de los estudiantes por el tipo de modalidad en que reciben las consignas de los docentes, sincrónica o asincrónica, discriminadas por tipo de institución según sean públicas o privadas.

Al analizar por nivel (primer ciclo versus segundo ciclo), también se obtuvo una asociación significativa entre el nivel y la modalidad que prefieren los estudiantes para recibir las consignas $\left(X^{2}=5.812\right.$, con $1 \mathrm{gl}$, nivel de significación $\mathrm{p}=0.05$ ). Mientras la modalidad asincrónica de formato texto tuvo una adhesión de $74 \%$ en primer ciclo, para segundo ciclo la preferencia estuvo en la modalidad sincrónica de videoconferencias con una tendencia menos marcada de $53 \%$ (Figura 2). Cuando un $69 \%$ de los estudiantes de bachillerato expresan que se comunicaron con sus docentes vía zoom (Cabrera Borges, Canziani, Martínez, 2020), se aprecia una congruencia similar a lo que ocurre con la preferencia por los medios sincrónicos de los estudiantes de instituciones privadas.

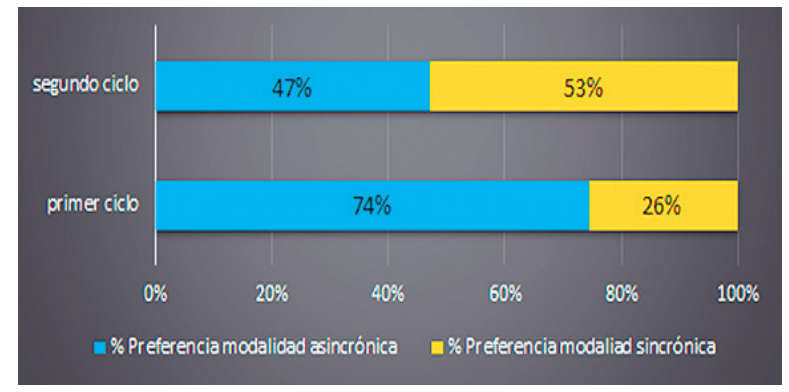

Figura 2. Porcentaje de preferencia de los estudiantes por un tipo de modalidad en que reciben las consignas de los docentes, sincrónica o asincrónica, discriminados por nivel en primer y segundo ciclo. 
A partir de dichos hallazgos es posible inferir que los estudiantes suelen identificar como la vía que más favorece la compresión de la consigna, aquella que coincide con las experiencias que tuvo al momento de comunicarse con sus docentes en el período de virtualidad absoluta. Dicho aspecto está en concordancia con lo expresado en Cabrera Borges, Canziani, Martínez (2020), respecto a que los estudiantes manifiestan una mayor preferencia por lo que más conocen.

Otra consideración posible a partir de tales resultados, es que la comunicación sincrónica podría ser menos elegida por los estudiantes de menor edad porque los expone más ante sus pares que la asincrónica (González y Liberati, 2020).

La utilización de la modalidad asincrónica por parte de estudiantes de primer ciclo también podría atribuirse a la retroalimentación personalizada que reciben por parte del docente. A partir de lo mencionado se formula la interrogante: $¿ E s$ posible que se haya priorizado realizar y recibir consultas y comentarios "directos con el docente a destiempo" respecto a realizar ese intercambio frente a sus compañeros?.

La preferencia de los estudiantes de menor edad, por recibir las consignas en formatos de modalidad asincrónica, ¿puede deberse a que, estos formatos les permitía obtener ayuda de otros actores de su entorno, del ámbito familiar?

\subsection{Tipos de recursos utilizados que les permitía comprender mejor}

Al ser consultados los estudiantes sobre qué tipos de recursos les permitían comprender mejor las propuestas que recibían de sus docentes, un $69 \%$ señala que comprendía mejor cuando se incluían textos con imágenes seguido de un $43 \%$ que prefería que incluyera videos y muy por debajo se encuentran las preferencias por las propuestas que incluían recursos como juegos o simuladores (17\%) o que consistían en sólo textos (14\%) (Figura 3).

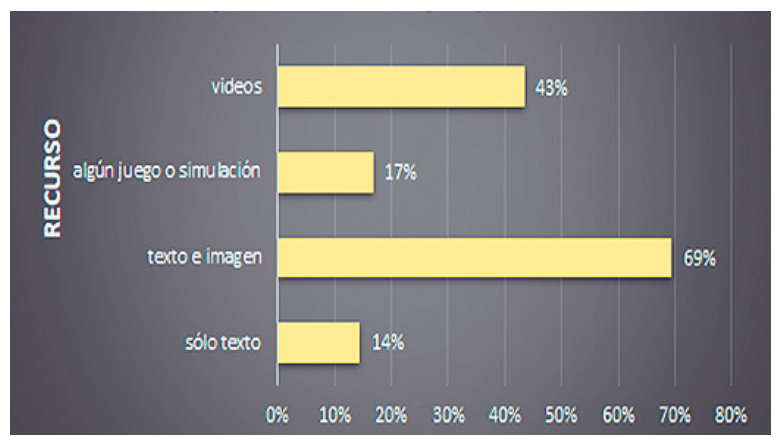

Figura 3. Porcentaje del tipo de recurso que los estudiantes prefieren que incluya una propuesta para comprender mejor.

Se encontró que la preferencia por el tipo de recurso que incluían las propuestas es independiente del tipo de institución (pública o privada) $\left(\mathrm{X}^{2}=1.914\right.$, con $3 \mathrm{gl}$, nivel de significación $p=0.05$ ) y del nivel según sea primer o segundo ciclo $\left(X^{2}=4.498\right.$, con $3 g l$, nivel de significación $\mathrm{p}=0.05$ ).

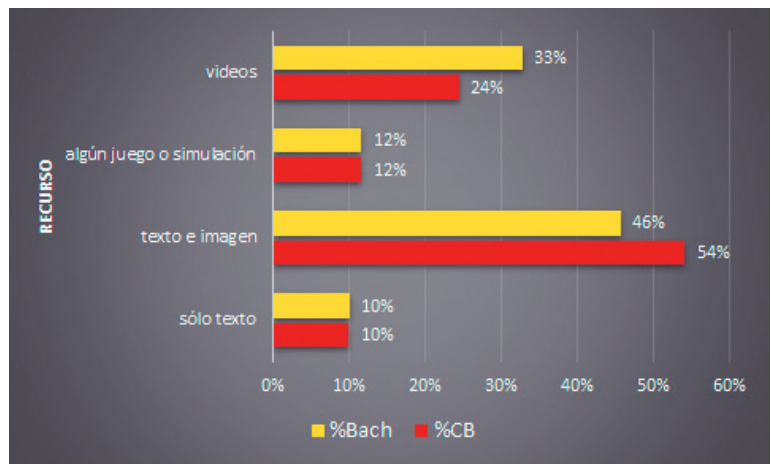

Figura 4. Porcentaje del tipo de recurso que prefieren los estudiantes que incluyan las propuestas docentes, para comprender mejor discriminado por nivel según sea bachillerato o ciclo básico.

La preferencia por recursos que incluyen texto e imagen es coherente con lo propuesto por las teorías cognitivas vinculadas al aprendizaje multimedia en la que se destaca la potencialidad de los recursos que aprovechan al mismo tiempo lo verbal y no verbal (Mayer, 2014). Desde esa lógica, sin embargo, los porcentajes correspondientes a videos, a pesar de que no fueron bajos, podrían haber sido más elevados. En el caso de los juegos y simuladores las preferencias están muy por debajo de lo esperado. Esto podría deberse a un escaso uso de los mismos por parte de los docentes en las propuestas implementadas en la virtualidad exclusiva, o a la falta de previsión del tiempo que insumirá la utilización de los mismos por parte de los estudiantes y que podría repercutir en el tiempo que les quede disponible para dedicarle a otras asignaturas o a actividades más afines a sus intereses (Katzir et al., 2020). Otro aspecto que puede explicar la menor preferencia por recursos como los videos, es que las propuestas pedagógicas en las que fueron incluidos, no proveyeron de herramientas que permitieran al estudiante jerarquizar y contextualizar los contenidos (Lion; 2021). 


\subsection{Tipo de actividades solicitadas en las tareas que les ayudaba para aprender}

Al analizar a través de qué tipo de tareas los estudiantes manifiestan que aprenden mejor, encontramos que un $70 \%$ indica que responder preguntas es la actividad que le ayuda a un mayor aprendizaje. Por otra parte, ninguno de los restantes tipos de tareas propuestas alcanzaron el $30 \%$ de las preferencias (Figura 5).

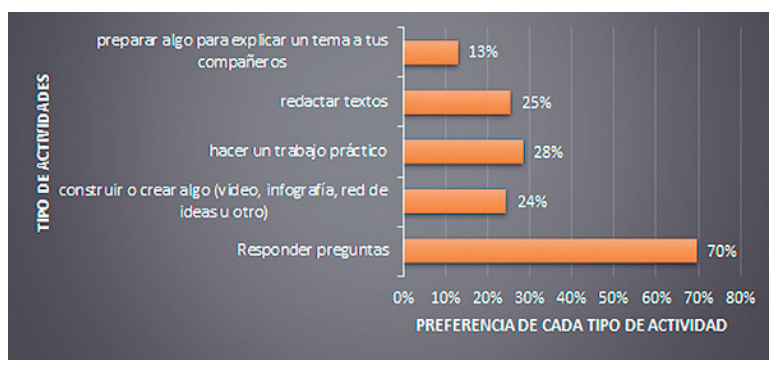

Figura 5: Preferencias del tipo de actividades a realizar que los estudiantes manifiestan que les permite un mejor aprendizaje.

De los resultados obtenidos se desprende que tanto los estudiantes de instituciones públicas como privadas indican que aprenden mejor con actividades que implican responder preguntas: $71 \%$ y $65 \%$, respectivamente. Además, las preferencias de los estudiantes de instituciones privadas estuvieron en las propuestas de redactar textos (36\%) y en las instituciones públicas prefirieron las tareas que incluían algún trabajo práctico (26\%). La asociación entre la preferencia por realizar algún tipo de actividad en particular con el tipo de institución es estadísticamente significativa ( $=9.77$; con $4 \mathrm{gl}$, nivel de significación $p=0.05$ ) mientras que el patrón de las actividades que prefieren los estudiantes de instituciones públicas y privadas no presenta diferencias significativas estadísticamente $(t=$ $1,44 ; g l=8 ; p<0,05)$. Esto último, posiblemente, podría estar indicando que los estudiantes muestran preferencias por un patrón de actividades conocido o que aplican con más frecuencia los docentes y que este patrón es similar en ambos tipos de institución. No se encontró una asociación significativa estadísticamente ( $=0.455$; con $4 \mathrm{gl}$, nivel de significación $p=0.05$ ) entre la preferencia por algún tipo de actividad y el nivel que cursa el estudiante (bachillerato o ciclo básico).

La amplia preferencia por responder preguntas puede deberse a que, además de ser una práctica muy frecuente, presenta múltiples potencialidades entre las que se destaca el ayudar al estudiante a focalizarse en los aspectos principales de lo que se pretende que aprendan (Rubio, et al, 2020). Presumiblemente este tipo de tareas le implicaba un menor costo en tiempo al estudiante, a diferencia de otras actividades que requirieron además de la comprensión de los contenidos, una mayor solvencia en el manejo de recursos digitales para poder resolver la tarea, concordando con lo planteado por (Katzir et al, 2020). Estos aspectos pueden explicarse, también, con lo señalado por Lion (2021), de la importancia de dar herramientas para jerarquizar los conocimientos, donde las actividades de responder preguntas pueden haber sido las que más se aproximaron a ayudar a organizar los conocimientos en una situación de confusión e incertidumbre.

\subsection{Aprendizajes identificados por los estudiantes en tiempos de virtualidad exclusiva}

En lo que respecta a la identificación de aprendizajes, por parte de los estudiantes, se constató que algunos manifiestan no haberlos identificado o no emiten respuestas al respecto (35 casos), en tanto otros, ofrecen ejemplos concretos que permiten conocer qué aspectos fueron valorados como significativos durante las experiencias educativas vividas en los primeros tres meses de pandemia.

Dentro de los que sí lograron identificar aprendizajes, fue posible reconocer diferen- 
tes subcategorías dependiendo del ámbito al cual están vinculados esos aprendizajes. En la tabla 1 se presentan evidencias que ejemplifican testimonios de los estudiantes respecto a sus aprendizajes en los ámbitos: tecnológico, académico, personal, vincular u otros.

En relación a lo tecnológico existen respuestas referidas al conocimiento y al uso de herramientas tecnológicas.

En lo académico se destaca que valoran la relevancia de la presencialidad y de contar con los docentes para lograr aprendizajes. En algunos casos lo hacen de forma más explícita que otros. En general se pone de manifiesto el valor de la presencia de docentes y pares en expresiones como: "que me es mucho más fácil que me expliquen los temas personalmente antes que hacer solo tareas por internet." (E1); "En que no siempre es bueno no ir al liceo ya que al no socializar cara a cara y no pasar tiempo con amigos te estresa por lo que no puedes hacer bien las cosas y que es mejor concurrir al liceo presencial" (E193). Este aspecto es coincidente con la necesidad del "cara a cara" que manifestaron los docentes en la encuesta oficial realizada por ANEP (2020). Mientras algunos estudiantes hacen foco en la presencialidad perdida, otros resaltan las potencialidades de lo virtual como alternativa para mantener los procesos educativos en tiempos de crisis.

Por otra parte, aparecen aspectos referidos a lo personal que interesan especialmente en tanto dan cuenta de la toma de conciencia de los estudiantes respecto a la influencia que tuvo lo vivenciado en el desarrollo de su au- tonomía y responsabilidad para afrontar las tareas en tiempos de virtualidad exclusiva.

Finalmente, se identifican aspectos vinculares y su relevancia para lograr aprendizajes. Esto se encuentra en estrecha relación con la alerta que manifiesta UNESCO (2020), y con lo expresado por Furman (2020), respecto a la interdependencia que existe entre la interacción social y el logro de aprendizajes.

En el ítem "otros", aparecen cuestiones muy diversas y valiosas para profundizar la reflexión sobre la enseñanza y el aprendizaje "escuchando" las voces de los protagonistas. Una respuesta da cuenta que los aprendizajes no fueron solo por parte de los estudiantes, sino que ellos también estuvieron atentos a los aprendizajes que realizaron sus docentes en ese período y a la sobrecarga que les significó la inexperiencia de algunos docentes en el trabajo virtual: "Fue que si bien esto fue un reto para todos, tanto docentes como alumnos se pudo enfrentar bastante bien aunque en un principio los profes no tomaron muy en cuenta que nos estaban sobrecargando muchas veces para ser clases de materias/ temas nuevos por una pantalla" (E127). El sentimiento de sobrecarga vivenciado por los estudiantes y su influencia en la percepción de sus aprendizajes aparece en más respuestas como, por ejemplo: "Que los profesores sobrecargan a los alumnos con tareas y no aprendemos, solo escribimos" (E 281).

Tabla 1. Análisis de las ideas de los estudiantes respecto a los aprendizajes que valoraron durante el tiempo de virtualidad exclusiva 


\begin{tabular}{|c|c|c|c|}
\hline Categorías & Subcategorías & Ejemplo de evidencia & $\begin{array}{l}\text { Cantidad de } \\
\text { respuestas }\end{array}$ \\
\hline \multicolumn{2}{|l|}{ Tecnológicos } & Usar la plataforma crea (E68) & 34 \\
\hline \multirow[t]{6}{*}{ Académicos } & $\begin{array}{l}\text { Importancia de la } \\
\text { presencialidad }\end{array}$ & $\begin{array}{l}\text { Que debemos de valorar más las clases presenciales } \\
\text { y el tiempo que los profesores se tomaban cada día } \\
\text { para darnos su clase (E15) }\end{array}$ & 61 \\
\hline & $\begin{array}{l}\text { Relacionados con } \\
\text { asignaturas }\end{array}$ & Sobre el cuerpo humano en biología. (E288) & 17 \\
\hline & $\begin{array}{l}\text { Otros aspectos } \\
\text { académicos }\end{array}$ & Poder realizar tareas fácilmente (E141) & 16 \\
\hline & $\begin{array}{l}\text { Potencialidades de la } \\
\text { enseñanza virtual }\end{array}$ & $\begin{array}{l}\text { Que las clases pueden darse online con mayor } \\
\text { normalidad, más las presenciales, ya que en internet } \\
\text { hay mucho material que pueden usar los profesores } \\
\text { para explicar mejor sus temas (E334) }\end{array}$ & 10 \\
\hline & $\begin{array}{l}\text { Métodos de } \\
\text { enseñanza }\end{array}$ & La enseñanza por otros métodos (E212) & 7 \\
\hline & $\begin{array}{l}\text { Importancia del } \\
\text { docente }\end{array}$ & A entender la importancia de un profe. (E41) & 6 \\
\hline \multirow[t]{3}{*}{ Personales } & Autonomía & $\begin{array}{l}\text { Que puedo hacer muchas cosas sola y sin ayuda de } \\
\text { nadie (E6) }\end{array}$ & 60 \\
\hline & Responsabilidad & $\begin{array}{l}\text { A ser responsable (no me fue bien) pero entendí que } \\
\text { es importante serlo (E147) }\end{array}$ & 23 \\
\hline & $\begin{array}{l}\text { Otros aspectos } \\
\text { personales }\end{array}$ & $\begin{array}{l}\text { Que lo que importa es querer aprender, no de qué } \\
\text { manera (E284) }\end{array}$ & 12 \\
\hline \multicolumn{2}{|l|}{ Vinculares } & A interactuar con mis compañeros de otra forma (E7) & 24 \\
\hline \multicolumn{2}{|l|}{ Otros } & $\begin{array}{l}\text { La importancia de poder zcostumbrarnos al contexto } \\
\text { en el que vivimos. (E5) }\end{array}$ & 83 \\
\hline
\end{tabular}

Nota: El código E corresponde a encuesta acompañado por el número de encuestado que figura en la base de datos construida para el análisis de las respuestas. Fuente elaboración propia.

\section{Reflexiones finales}

Los hallazgos obtenidos en el presente estudio muestran que el tiempo de virtualidad exclusiva habría tenido ciertas particularidades respecto a cómo los estudiantes consultados perciben las tareas que se les presentaron en relación con sus aprendizajes. Dichas particularidades tienen varias coincidencias con la descripción de la enseñanza remota de emergencia que hicieran Hodges et. al (2020).

La situación de confinamiento exclusivo a causa de la pandemia, significó una drástica modificación tanto de la dimensión espacial como temporal en las que ocurren los eventos de enseñanza aprendizaje en la educación formal. La dimensión espacial convencional, fue anulada al cesar la actividad presencial y lo espacial se fragmentó en la realidad particular de cada uno, de cada hogar. Esto implicó dificultades que cada actor tuvo que enfrentar solo, tanto el docente que debió transformar en aula su hogar como el estudiante que también se vio obligado a exponer su intimidad. Esta situación física también alteró la dimensión temporal que transcurría entre el contexto tecnológico y el hogar. Los docentes no sólo debieron reformular sus propuestas pedagógicas, sino que en lo temporal se agregaron múltiples dificultades, tanto las que implicaba el manejo temporal de los recursos y herramientas digitales, así como también los horarios que debieron ajustarse a los de los hogares. Es sobre esa condición alterada de las dimensiones espacio - tiempo, que debe reinventarse la enseñanza en línea por lo que entendemos ajustado considerar esta situación como una educación remota de emergencia (Hodges et. al, 2020)

La falta del "cara a cara" no solamente parece haber significado una dificultad para los docentes que debían 
pensar propuestas para un auditorio del que prácticamente desconocían necesidades e intereses, sino que también fueron un desafío para quienes debían realizar aprendizajes en ese contexto tecnológico. Es así que la alternativa parece haber sido esperar lo mismo que recibían en tiempos de presencialidad, pero ahora, a través de un formato virtual.

En ese marco de emergencia sanitaria y educativa corresponde plantear algunas preguntas como: ¿Qué lugar tuvo el aprendizaje? ¿Cuáles fueron los propósitos educativos de docentes, estudiantes y familias en tiempos de virtualidad exclusiva? Los acuerdos tácitos que existen en la presencialidad ¿permanecieron o se desvanecieron? Transferir lo que ya se hacía modificándolo lo menos posible ¿se transformó en un "acuerdo implícito"?

Las expectativas que manifiestan los estudiantes respecto a cómo aprendían mejor en tiempos de virtualidad exclusiva no guardan total relación con lo esperado desde la búsqueda de un aprendizaje virtual de calidad. Esto podría deberse al escaso tiempo de preparación de los docentes y estudiantes para trabajar en esa modalidad y, a la necesidad de dar continuidad a las prácticas educativas, para lo cual lo ya conocido resulta más rápido y ofrece menos incertidumbres. Es posible que las dificultades en el diseño y planificación de la enseñanza remota pudieran llevar a adaptar lo ya conocido a la propuesta virtual o que, simplemente, los docentes pensaran que el diseño de la enseñanza virtual puede hacerse con la transferencia idéntica del formato de la presencialidad, sin darse oportunidad para pensar en algo nuevo. Un ejemplo concreto de resultados escasamente esperados es que en un tiempo en el que los adolescentes parecen estar inmersos en el lenguaje audiovisual, los videos no ocupan el primer lugar al momento de caracterizar las propuestas que los ayudan a comprender mejor. Algunas explicaciones posibles podrían estar relacionadas a las características de la enseñanza remota de emergencia, en la que los docentes posiblemente no contaran con los tiempos necesarios para seleccionar videos que captaron el interés de los estudiantes, o que cumplieran con las características sugeridas para que tuvieran la extensión, atractivo y rigurosidad requerida para ese curso. En cuanto a la extensión, es necesario tener en cuenta las dificultades vinculadas con el acceso a internet que presentaron muchos estudiantes. Corresponde mencionar que los docentes consultados en el estudio que se citó como antecedente, expresan que la conectividad fue una de las dificultades que debieron afrontar los estudiantes en el tiempo de virtualidad exclusiva
(ANEP, 2020). Las restricciones vinculadas a la cantidad de datos que insume observar un video vuelven imprescindible adaptar dicho recurso ya sea cortándolo o pautando de dónde a dónde observar. A lo didáctico se pueden haber sumado dificultades tecnológicas vinculadas, por ejemplo, como ya mencionamos, a contar con la conexión a internet y con los dispositivos requeridos para ejecutar esos vídeos. En síntesis, la respuesta a esta paradoja tal vez pueda estar relacionada con los diversos problemas tecnológicos que se suscitaron y con el escaso desarrollo de competencias digitales de docentes y estudiantes.

En el caso de los juegos y las simulaciones llama todavía más la atención su escasa preferencia. ¿Es que los estudiantes prefirieron enfoques tradicionales a los lúdicos? ¿En qué medida habrán recibido ese tipo de propuestas para juzgar si les gustan? Será que si las recibieron ¿suponen un compromiso cognitivo mayor que cumplir con otro tipo de tareas? En un momento con un horizonte incierto, con mutaciones en los tiempos y formas del dispositivo escolar, de amenaza de las certezas, bajo situaciones de presión y de estrés, es más difícil utilizar la creatividad y resolver problemas.

En lo que respecta a la preferencia por responder preguntas, puesta de manifiesto por los estudiantes consultados, deja abierta la posibilidad de realizar nuevas indagaciones en las que se pueda profundizar a qué tipo de preguntas hacen referencia. De acuerdo con los datos obtenidos, no es posible valorar a cabalidad tal preferencia dado que bajo el rótulo de responder preguntas pueden estar incluidos diversos enfoques didácticos que van desde lo exclusivamente memorístico hasta alternativas que promuevan procesos cognitivos más complejos. La reflexión post emergencia podría aprovechar esta disposición de los estudiantes hacia ese tipo de prácticas para incentivar la generación de propuestas didácticas que incluyan el responder preguntas del tipo esenciales (Elder y Paul 2002), tanto para adquirir el hábito de formular preguntas de este tipo que estructuran el pensamiento en torno a sus elementos constituyentes, como a lo que es estructurante para la disciplina. Esto podría tener un rol importante para romper con la horizontalidad epistemológica de internet que nos plantea Lion (2021) y valorizar las propuestas que incluyen preguntas para introducir el hábito de pensar, en términos de los aspectos claves de cada tema, en un formato conocido por el estudiante y con un número de preguntas acotadas que le brinden certezas (Katzir et al, 2020; Smith y Karpicke, 2014), que posteriormente puede ser aprovechado en cualquier otro tipo de recurso multimedia. 
Los resultados del presente trabajo permiten inferir que los estudiantes prefirieron recibir la información por los canales que mejor conocían; que comprenden mejor las tareas cuando se presentaba con recursos conocidos o que explotaban más de un canal de procesamiento de la información y que les resultaban más productivas las actividades que les permitían enfocarse en aspectos conocidos o relevantes. En momentos donde es necesario maximizar los tiempos pedagógicos, es sumamente importante enfocar la enseñanza y el aprendizaje en lo que es clave aprender y la forma más eficiente de hacerlo. Estas impresiones que señalan los estudiantes sobre lo vivido en 2020 coinciden con lo que nos propone Lion (2021), respecto a dar herramientas para jerarquizar los conocimientos disciplinares, para visibilizar los procesos de pensamiento que permitan al estudiante ganar autonomía en su construcción de conocimientos y poder reconocer cuáles son las mejores estrategias para aprender y optimizar el uso del tiempo.

Es preciso mencionar, además, que los resultados obtenidos no son generalizables, sino que se remiten a la muestra relevada. Pueden haber quedado ideas relevantes fuera del relevamiento y por lo tanto del análisis, por ejemplo, de aquellos estudiantes que por falta de acceso a las tecnologías digitales (ya sea por falta de dispositivos o de conectividad), no hayan completado el formulario, considerando que el cuestionario en el que se basa este estudio se implementó en formato digital.

A modo de cierre, resulta inevitable formularse la pregunta: ¿en qué medida las experiencias educativas vividas en 2020 habrán preparado a docentes y a estudiantes para aproximarse a nuevas formas de aprender en las que las tecnologías digitales facilitan la transformación y no ofrezcan nuevos formatos para la misma enseñanza que se venía dando? La experiencia del 2020 puso a todos los actores, docentes y estudiantes, no en la opción sino en la obligación de apelar a las herramientas digitales para poder transitar los procesos de enseñanza aprendizaje. Esta aproximación obligada, sin duda que dejó aprendizajes sobre nuevas formas de aprender y enseñar, en las que las tecnologías digitales tuvieron un rol sin precedentes que van a permitir posicionarse de una manera diferente a los educadores y educandos en el futuro próximo. Cabe preguntarse: ¿esos aprendizajes sobre las tecnologías digitales, qué prácticas educativas y de qué manera, van a modificarse?; ¿esta experiencia, qué aspectos de la relación docente - estudiante va a modificar? Sin duda esta experiencia generó la oportunidad de gestar un cambio en las prácticas de enseñanza con incorporación genuina de TIC pero si no media reflexión este cambio no está garantizado.

\section{Referencias}

ANEP (2020). Situación educativa en el contexto de la emergencia sanitaria Encuesta Docente - ANEP 15 de julio de 2020 https://www.anep. edu.uy/sites/default/files/images/2020/noticias/ agosto/200825/1598288296799_Informe\%20 Encuesta\%20Docente\%20ANEP\%20-\%2015\%20 de\%20julio.pdf

Baddeley, A. D. (1986). Working memory. New York: Oxford University Press.

Burbules, N.; Callister T. (2006). Educación, riesgos y promesas de las nuevas tecnologías de la información. Buenos Aires, Granica. https://books. google.com.uy/books?hl=es\&lr=\&id=Y31MX9xOtr gC\&oi=fnd\&pg=PA3\&dq=Burbules, $+\mathrm{N} . \% 3 \mathrm{~B}+$ Callist er+T.+(2001).+Educaci\%C3\%B3n,+riesgos+y+prom esas+de+las+nuevas+tecnolog\%C3\%ADas+de+la+i nformaci\%C3\%B3n.+Buenos+Aires,+Granica, +200 $6 . \&$ ots $=Y 5 P m G 1 R 2 a Q \& s i g=0 U 650$ rpt8jSVOWBDR VTtrwR1ggw\&redir_esc $=y \# v=$ onepage $\& q \& f=$ false

Burin, D. I. (2020). Lectura y aprendizaje multimedia. TeseoPress. https://www.teseopress.com/ competencialectora/chapter/natalia-irrazabal/

Butler, A. C., Marsh, E. J., Goode, M. K., \& Roediger, H. L. (2006). When additional multiple-choice lures aid versus hinder later memory. Applied Cognitive Psychology, 20, 941\#956 https://onlinelibrary. wiley.com/doi/abs/10.1002/acp.1239

Cabero, J.; Román, P. (coord) (2006). E-actividades. Un referente básico para la formación en Internet. Sevilla: Editorial MAD-Eduforma https://www. redalyc.org/pdf/706/70601014.pdf

Cabrera, C., Canziani, C., Martínez, G. (2020) Las estrategias de comunicación en

tiempos de virtualidad exclusiva: análisis desde la mirada de los estudiantes. Didáctica. Educación Media. , 7, 43-57.

CEPAL, N. (2020). La educación en tiempos de la pandemia de COVID-19. https://repositorio.cepal. org/bitstream/handle/11362/45904/S2000510_ es. pdf?sequence=1\&isAllowed=y

Cuestas, J. M., González, C., \& Liberati, J. R. (2020, September). Actividades sincrónicas y asincrónicas: Virtudes y falencias. In Memorias de las Jornadas 
Nacionales y Congreso Internacional en Enseñanza de la Biología (Vol. 2, No. Extraordinario, pp. 203203).

http://congresos.adbia.org.ar/index.php/congresos/ article/view/94

Elder, L.; Paul, P. (2002). El arte de formular preguntas esenciales. Foundation for Critical Thinking. https://www.criticalthinking.org/resources/PDF/ SP-AskingQuestions.pdf

Fardoun, H., Yousef, M., González-González, C., Collazos, C. A. (2020). Estudio exploratorio en Iberoamérica sobre procesos de enseñanzaaprendizaje y propuesta de evaluación en tiempos de pandemia. https://repositorio.grial.eu/ bitstream/grial/2091/1/23537-79772-1-SM.pdf

Failache, Elisa, Katzkowicz, Noemí, Machado, Alina. La educación en tiempos de pandemia. Y el día después. [en línea ].Blog del Departamento de Economía, 3 abril 2020. http://http:// fcea.edu.uy/images/dto_economia/Blog/ La_educaci\%C3\%B3n_en_tiempos_de_ pandemia._Y_el_d\%C3\%ADa_despu\%C3\%A9s.pdf

Fullan, M. y Langworthy, M. (2014). Una rica veta. Cómo las nuevas pedagogías logran el aprendizaje en profundidad. Londres: Pearson.

Furman, M. (2020, abril) Nuevas formas de aprender y enseñar a partir de la pandemia TEDxRiodelaPlata https://www.youtube.com/ watch?v=TgrOmfEYhUs

Hodges, C., Moore, S., Lockee, B., Trust, T., \& Bond, A. (2020). The difference between emergency remote teaching and online learning. Educause review, 27, 1-12.https://er.educause.edu/articles/2020/3/ the-difference-between-emergency-remoteteaching-and-online-learning

Katzir, M., Emanuel, A., \& Liberman, N. (2020). Cognitive performance is enhanced if one knows when the task will end. Cognition, 197, 104189. https://doi.org/10.1016/j.cognition.2020.104189.

Lion, C. (2021, febrero) Docencia en contextos híbridos. Escuela de verano 2021. [Archivo de video]. You Tube. https://youtu.be/INGWRbFY8ww

McDaniel, M. A., Roediger, H. L., \& McDermott, K. B. (2007). Generalizing test-enhanced learning from the laboratory to the classroom. Psychonomic bulletin \& review, 14(2), 200-206.

Mayer, R. \& Moreno, R. (1998). A split-attention effect in multimedia learning: Evidence for dual processing systems in working memory. Journal of Educational Psychology, 90, 312-320.

Mayer, R.E. (2001). Multiimedia learning. Nueva York: Cambridge University Press.

Marsh, E. J., Agarwal, P. K., \& Roediger III, H. L. (2009). Memorial consequences of answering SAT II questions. Journal of Experimental Psychology: Applied, 15(1), 1.

Mayer, R.E. (2014). The Cambridge Handbook of Multimedia Learning (Cambridge Handbooks in Psychology). Cambridge: Cambridge University Press. https://bit.ly/2SqAXrh.

National Research Council 2000. How People Learn: Brain, Mind, Experience, and School: Expanded Edition. Washington, DC: The National Academies Press. https://doi.org/10.17226/9853

Park, J. (2005). Learning in a new computerised testing system. Journal of Educational Psychology, 97, 436-443. https://psycnet.apa.org/ record/2005-11263-010

Pyc, M. A., \& Rawson, K. A. (2009). Testing the retrieval effort hypothesis: Does greater difficulty correctly recalling information lead to higher levels of memory?. Journal of Memory and Language, 60(4), 437-447. https://www.sciencedirect.com/ science/article/abs/pii/S0749596X09000138

Rubio, A., Vidal, E.,\& Martinez, T. (2020). Selfexplanation versus question-answering: Differences in processing and effectiveness for learning complex conceptual knowledge. (Tesis). Universidad de Valencia. España. https://roderic. uv.es/handle/10550/76627

Salomón, P. (2012). Integración de la tecnología educativa en el aula: enseñando biología con las TIC. Cengage Learning.

Schnotz, W., \& Lowe https://www.tandfonline.com/ doi/abs/10.1080/09658211.2013.831454, R. K. (2008). A unified view of learning from animated and static graphics. Learning with animation: Research implications for design, 304-356. https:// books.google.com.uy/books?hl=es\&lr=\&id=6k8 vKcX8BwC\&oi=fnd\&pg=PA304\&dq $=$ Schnotz,$+W$ ., +\%26+Lowe,+R.+K.+(2008).+A+unified+view+o $\mathrm{f}+$ learning+from+animated+and+static+graphic s.+Learning+with+animation:+Research+implica tions+for+design,+304-356.\&ots=XgQZOBC4IJ\& sig=BK8pM6gYC51eeQtHOZ-cfhRWtmw\&redir_ esc $=\mathrm{y} \# \mathrm{v}=$ onepage $\& \mathrm{q} \& \mathrm{f}=$ false 
Smith, M. A., \& Karpicke, J. D. (2014). Retrieval practice with short-answer, multiple-choice, and hybrid tests. Memory, 22(7), 784-802.

UNESCO, 2020 "Consecuencias adversas del cierre de las escuela" recuperado de https://es.unesco.org/ node/320395

VALVERDE B, J. (2002). Herramientas de comunicación sincrónica y asincrónica. Educar en red. Internet como recurso para la educación. 